\title{
Hermenéutica simbólica: la poética simbólica de Juan Eduardo Cirlot*
}

\section{Symbolic Hermeneutic: The Symbolic Poetry of Juan Eduardo Cirlot}

Alfonso Castillo

Lingüística General y Teoría de la Literatura

Universidad de Granada

Campus de Cartuja s/n. Granada, 18071

ubealf@correo.ugr.es

Orcid ID 0000-0001-5453-2297
Resumen: En este artículo exploramos el concepto de símbolo como vínculo con lo desconocido y originario desde distintos puntos de vista, como el antropológico y el místico. A continuación, revisamos las ideas sobre poesía de Juan Eduardo Cirlot para encontrar en ellas características comunes entre su concepción de la poesía y la visión del símbolo que hemos descrito. Seguiremos una metodología hermenéutica por la que pretendemos mantener un diálogo con los textos teóricos de Cirlot y abrir nuevas perspectivas sobre ellos. Nuestras hipótesis interpretativas se fundamentan en la lectura detenida de los textos del autor, entre ellos su Diccionario de símbolos, sus artículos y su obra poética Bronwyn. El hecho de que el concepto de símbolo y cierta visión de la poesía tengan en común el ser un vínculo hacia un territorio desconocido propio del ser humano nos lleva a concluir que sería posible hablar de "poesía simbólica".

Palabras clave: Cirlot. Poesía. Simbolismo. Hermenéutica simbólica. Bronwyn.
RECIBIDO: 19 DE SEPTIEMBRE DE 2017 ACEPTADO: 9 DE FEBRERO DE 2018

\begin{abstract}
In this article, we explore the concept of symbol as a link with the unknown from different points of view, as the anthropological and the mystical. Then we review the ideas about poetry of Juan Eduardo Cirlot to find in them common features between his conception of poetry and the vision of the symbol that we have described. Our hermeneutic methodology consists in a dialogue with the theoretical texts of Cirlot from which we extract new ideas, recognizing that we cannot be sure of having found the "sense of the author", but at least doing an interpretation based on the original texts, as his Dictionary of Symbols, his articles or his poetic book Brownyn. We state that the concept of symbol and a particular vision of poetry have in common to be a link to an unknown territory of the human being, which enables us to speak about "symbolic poetry".
\end{abstract}

Keywords: Cirlot. Poetry. Symbolism. Symbolic Hermeneutic. Bronwyn.

\footnotetext{
* Este trabajo se ha realizado en el marco del proyecto de investigación "Actualidad de la hermenéutica" (FFI2013-41662-P), financiado por el Ministerio de Economía y Competitividad para el periodo 2014-2018.
} 


\section{INTRODUCCIÓN Y METODOLOGÍA}

E n el siguiente artículo vamos a explorar el concepto de símbolo desde varios puntos de vista. En especial, nos interesa del símbolo su visión como unión, como vínculo con algo desconocido, misterioso, lejano, puesto que, en este sentido, el símbolo tiene una relación muy cercana con cierta poética que, por ello, denominaremos simbólica. Asimismo, trataremos de mostrar que un claro ejemplo de poética simbólica es la desarrollada por Juan Eduardo Cirlot, tanto en lo teórico, como en lo práctico.

Desde el punto de vista metodológico, nuestra pretensión en este artículo es más de tipo teórico que crítico. Nuestra intención principal es hacer un repaso por los textos teóricos de Juan Eduardo Cirlot para trazar las ideas básicas de su poética en relación con la idea de símbolo como vínculo. Si en ocasiones aportamos un poema de Cirlot, es más con la intención de ilustrar la teoría que para realizar un trabajo de crítica literaria. También estudiaremos la concepción sobre el símbolo realizada desde la antropología, a través del autor Luis Garagalza, y el misticismo, para lo que nos servirá de base Henry Corbin; ya que ambas perspectivas coinciden con la teoría poética de Cirlot en considerar al símbolo como un vínculo hacia aspectos esenciales y desconocidos del ser humano.

Como afirma Sultana Wahnón en Saber literario y hermenéutica: "El deseo de entender exactamente lo que quiso decir el autor del texto es sustituido, en la moderna teoría de la interpretación, por el deseo mucho más 'débil' -en realidad, apenas deseo- de mantener un fecundo diálogo con él” (1991, 94). En este artículo, intentaremos mantener un diálogo con las ideas teóricas sobre poesía de Juan Eduardo Cirlot, de modo que descubramos la cercanía que puede haber entre cierta visión de lo poético con el concepto de símbolo, sin olvidar, como ha escrito más recientemente la misma Wahnón $(2014,63)$, que la interpretación exige una ética por la cual no hagamos decir al texto lo que queramos o lo que nos convenga, de modo que intentaremos, como también defiende Wahnón, en una línea cercana a Ricoeur, tener en cuenta el "sentido del autor" como una "dimensión del texto" por más que no podamos tener la total seguridad de haber dado con él $(2014,51)$.

\section{El SÍMBOLO COMO VÍNCULO}

El símbolo es un concepto complejo que cuenta con una larga tradición y ha sido abordado desde muchos puntos de vista. Por ejemplo, varios autores del 
Romanticismo alemán escribieron sobre él. Entre ellos, Goethe, en su texto "Sobre el símbolo", lo define haciendo mención de lo inefable de aquello a lo que se refiere: "Es la cosa sin ser la cosa, y, sin embargo, la cosa; una imagen concentrada en el espejo del espíritu, y, sin embargo, idéntica con el objeto. [...] pues, con todo, aquello de lo que se trata no se pronuncia con palabras" (166).

Nos interesa especialmente la definición del símbolo que podemos encontrar en el misticismo y la antropología, porque abren la posibilidad de relacionar el símbolo con una visión introspectiva e individualista de la poesía. Esto es, con una visión de la poesía en la que, como escribió Octavio Paz, "El poeta dice y, al decir, hace. Este hacer es sobre todo un hacerse a sí mismo. La poesía no es solo autoconocimiento, sino autocreación" (192-93). En las definiciones que se pueden hacer del símbolo hay un aspecto que siempre aparece: el símbolo es un vínculo -más que una representación, puesto que, como veremos, hace referencia a algo de suma dificultad representativa-. El símbolo, entendido en el terreno personal, une al ser humano con un ámbito propio del cual se encuentra alejado y que a través de la poesía (simbólica, vinculante) es posible conocer y, a la vez, desarrollar.

Desde el punto de vista antropológico, Luis Garagalza (2002, 89-93) usa para hablar del símbolo los términos naturaleza y cultura; con el primero de ellos se refiere a lo originario, a lo primitivo, del ser humano y, con el segundo, al camino de separación por el que nos hemos distanciado de lo referido por el primer término. Para hablar del origen del símbolo en la cultura, Garagalza pone el ejemplo de la tribu de los watchandis, quienes cavan un agujero antes de iniciar la labranza y danzan alrededor, de modo que la parcela de tierra queda investida con una imagen femenina: el agujero se asimila simbólicamente, se confunde, con el órgano genital de la mujer, que está directamente relacionado con la fertilidad. De este modo, el hombre en una fase primitiva -en el sentido de más apegada a lo natural- necesita de una mediación simbólica para emprender una actividad cultural, que se despliega en un rito ejecutado de un modo cuasi-instintivo, más o menos inconsciente, y en un mito que es la narración que lo interpreta. En una fase posterior de la evolución cultural se conquista la fuerza de voluntad y control consciente para actuar en contra de las tendencias naturales y, cuando ese desarrollo se consolida, se puede prescindir de la mediación del rito y del mito correspondiente y acometer directamente la tarea, de modo que el símbolo se va convirtiendo en un mero signo. Así, siguiendo con el ejemplo anterior, el foso podría llegar a ser el emblema de un sindicato de trabajadores agrícolas. Para Garagalza, el 
signo es un símbolo que pierde su eficacia psico-social y se convierte en una mera representación convencional.

Por tanto, desde el punto de vista de Garagalza, en el proceso simbólico la imagen sensible (natural) se vincula o confunde con algo radicalmente nuevo, distinto y que la trasciende y que tiene un sentido cultural. De este modo, el símbolo se sitúa como vínculo entre el aspecto natural del ser humano -relacionado con el instinto- y el cultural. Así pues, el símbolo es una realidad ambigua caracterizada por una tensión creadora que nunca llega a resolverse: he aquí el aspecto misterioso, trascendental, de significado abierto, que caracteriza al símbolo y que lo emparenta con cierto modo de entender la poesía. Según esto, la imagen siempre es insuficiente en sí misma para expresar el sentido simbólico y, a su vez, el sentido simbólico siempre quiere decir más que la imagen de por sí.

Por otro lado, desde un punto de vista místico y oriental, Henry Corbin (37-78) habla de una realidad imaginal, la cual, como el símbolo, es una realidad unitiva que se encuentra como mediadora entre distintos ámbitos del ser humano. Según Corbin, Imaginal es

la Realidad que se corresponde con la percepción imaginativa, con lo imaginario, lo irreal. Entre un universo constituido por elementos meramente físicos y una subjetividad que se aísla, ofrecemos la necesidad de un mundo intermedio que una ambos, algo semejante a un reino espiritual de los cuerpos sutiles. Este es el mundo intermedio sobre el que no han dejado de meditar, sobre todo en el Irán islámico, además de los maestros sufíes, los adeptos de la filosofía de Suhrawardī de la luz y los de la gnosis chí́ta. Este mundo intermedio ya no es solo el centro del mundo como Ērān-Vēj, sino el centro de los mundos. El mundus imaginalis, mundo de las Formas y realidades imaginales, se establece como mediador entre el mundo de las puras esencias inteligibles y el universo sensible. (78)

Según el concepto de símbolo que vemos desde estas perspectivas, el ser humano convive con un ámbito natural y trascendental propio y el símbolo es un vínculo hacia ello. Ese lado imaginal, no sensible, del ser humano, como diría Corbin, o natural, como diría Garagalza es misterioso y entraña dificultad representativa, escapando siempre su significado a la representación o significante que trata de referirlo. De hecho, Gilbert Durand caracteriza al símbolo por tratarse de un caso en que "el significado es imposible de presentar y el signo solo puede referirse a un sentido, y no a una cosa sensible" (12-13). Como 
explica Garagalza (1990, 49-50), Durand distingue el símbolo del signo, el cual entiende como un mecanismo de economía consciente basado en una imagen significante arbitraria asociada a un significado, y de la alegoría, donde lo que se quiere significar no puede presentarse directamente por tratarse de abstracciones, cualidades morales o espirituales, etc. Pero la alegoría parte de una idea para llegar a ilustrarla en una figura, mientras que el símbolo es inverso a la alegoría: el símbolo es una figura en sí que contiene un significado que lo trasciende; es decir, el símbolo es fuente de ideas.

A partir de estas concepciones teóricas del símbolo veremos cómo se trata de un concepto básico y definidor para cierto tipo de poética, como la de Juan Eduardo Cirlot, que entiende la poesía como una expresión de ese lado humano recóndito, desconocido, introspectivo, que no podemos vivir a través de nuestros sentidos y circunstancias.

\section{La PoÉtica Simbólica de Juan Eduardo Cirlot}

\section{La poesía como sustituto de lo que el mundo no es y no da}

La filosofía imaginal que hemos comentado de Corbin influyó en la poética simbólica que pretendemos explicar de Cirlot, quien escribió un ciclo de poesía dedicado a un personaje que aparece en la película El señor de la guerra (1965) de Franklin Schaffner. Se trata de una dama celta llamada Bronwyn que vivía en el siglo $\mathrm{x}$ en un pueblo de la Bretaña francesa y al que se refiere la voz poética de modo amoroso, pero frustrado debido a la lógica ausencia de Bronwyn o, dicho de otro modo, por lo imposible de su presencia. En el ciclo poético titulado Bronwyn, el personaje al que se dirige la voz poética, pese a ser una imagen artística propia del campo de la ficción, es tratado como una realidad imaginal, como una realidad a la que no puede accederse mediante los sentidos, como sí ocurre con los objetos del mundo sensible, porque pertenece al campo de lo imaginativo, pero no por ello menos real. Por ejemplo, en el siguiente poema de Bronwyn, VI (1969), la voz poética afirma que en su mundo no se encuentra el cuerpo de Bronwyn:

Órbitas de ceniza en la mirada:

negaré siempre un mundo en que no está

tu eternamente cuerpo. (1969a, 208)

Asimismo, en este otro poema de la misma obra perteneciente al ciclo de Bronwyn, la voz poética sostiene que nunca ha podido tener un encuentro pre- 
sencial con Bronwyn y que su sentido del tacto no puede percibirla, sino que por el contrario solo se hunde en el vacío:

Nunca ha habido un encuentro.

Hay resplandores verdes y temor, ceniza y humedad, desesperados dedos que ahondan el vacío. (1969a, 209)

Como puede verse, el personaje de ficción Bronwyn al que se refiere la voz poética es una realidad que se caracteriza por su ausencia sensible, pero con la que se puede establecer una conexión a través de la poesía, porque, como se ha dicho, Cirlot entendía la poesía de modo simbólico, es decir, como una conexión hacia lo desconocido, misterioso, inaccesible a través de los sentidos. Por eso, cuando José Cruset pregunta a Cirlot en una entrevista sobre su interés en la abstracción, el poeta responde:

Mi interés por la abstracción, en arte, se debe a que niega el mundo exterior, el de la evidencia de los sentidos, el de la realidad odiosa y odiada. Mi actual pasión por el gótico se comprende al leer lo que Worringer dice de ese arte "afán dinámico de espacios y mundos diferentes", en resumen. Y mi poesía es un esfuerzo por encontrar el umbral de la ultrarrealidad. Busco un verso que, en su línea (a la fuerza simple y melódica) sea la síntesis de una polifonía, de modo que la estrofa sea una "polifonía de polifonías", una compleja estructura de procesos análogos, densa y a la vez transparente. Y luego intento que esa poesía sustituya, para mí, lo que este mundo no es, y no me da. (Cruset 58)

Puesto que, para Cirlot, la poesía sustituye lo que el mundo no es y no le da, en esta misma entrevista añade: "vivo en lo imposible" (Cruset 58). En esta respuesta se refiere con "este mundo" al mundo sensible, mientras que la poesía la entiende como un vínculo al lado natural e imaginal de su ser. Por tanto, para él la poesía funciona -y esto es lo que tiene en común con los símbolosde un modo unitivo con lo desconocido personal y, sirve, a la vez, para descubrirlo. Además, entiende que la poesía está dotada de una significación trascendental, plural y abierta.

Por este motivo, encontramos poemas sobre Bronwyn en los que se declara que ella no se encuentra en el mundo exterior y sensible, sino en el interior, de modo que el camino para conectar con ella es el poético-simbólico. Tal búsqueda de lo sagrado en el interior es, además, un aspecto de la poesía de Cirlot que comparte con la poesía mística: 
Cuando todo se invierte

en el bosque me buscan y es tu voz

en el ávido abismo de mí mismo;

me buscan entre trozos, entre pozos;

me buscan sin saber que soy el bosque.

Nunca te encontraré porque el encuentro

habría ser fuera y estás dentro. (Cirlot 1971b, 501)

Es muy significativa la cita de Hebbel que Cirlot elige para encabezar el "Prólogo a la segunda edición" de su Diccionario de símbolos: "El deber más importante de mi vida es, para mí, el de simbolizar mi interioridad" $(1958,11)$. Aplicándolo al propio Cirlot, podemos decir que pretende con la poesía iluminar, desvelar, desenterrar, partes ocultas, no conscientes de su identidad personal a través de la poesía, lo cual se asemeja al concepto de símbolo como vínculo que se está trazando aquí. Cirlot pretende con la poesía conectar con su naturaleza profunda, con su mundo imaginal, con su subconsciente. De ahí su parcial relación con el surrealismo, que tanto ahonda en el subconsciente y en los sueños -véanse obras de Juan Eduardo Cirlot como 80 sueños de 1951-, pero su poesía se aleja del surrealismo por no ser una escritura automática, sino consciente.

Sin embargo, para completar el plano del símbolo, hemos de comentar que este no solo es entendido por Cirlot en el ámbito del ser humano individual como microcosmos, sino que también entiende el símbolo como vínculo dentro de la Creación. Así la segunda cita que Cirlot elige para ese "Prólogo a la segunda edición" de su Diccionario de símbolos es: "El mundo es un objeto simbólico" $(1958,11)$, de Salustio. Si para el apartado individual la influencia en Cirlot es Corbin, para el símbolo en el macrocosmos fue una fuerte inspiración el concepto de ritmo común de Marius Schneider, autor de El origen musical de los animales-símbolos, con quien Cirlot llegó a mantener una relación de amistad personal e intelectual durante el periodo en que Schneider vivió en Barcelona. Schneider entendía las formas sensibles del universo como ordenadas musical y simbólicamente entre sí, una concepción simbólica que comenta Cirlot del siguiente modo en su "Introducción" al Diccionario de símbolos:

Mientras la ciencia natural establece solo relaciones entre grupos "horizontales" de seres, siguiendo el sistema clasificador de Linneo, la ciencia mística o simbólica lanza puentes "verticales" entre aquellos objetos que 
se hallan en un mismo ritmo cósmico, es decir, cuya situación está en "correspondencia" con la ocupada por otro objeto "análogo", pero perteneciente a un plano diferente de la realidad; por ejemplo, un animal, una planta, un color. $(1958,38-39)$

Por otro lado, llama la atención que el título de la primera edición de 1958 de este diccionario fuera Diccionario de simbolos tradicionales, pero que en la segunda edición de 1969 Cirlot cambiara tal título eliminando el último término para quedar solo como Diccionario de símbolos. No obstante, en el "Prólogo a la segunda edición" sigue considerando que su diccionario tenía un valor universal por haber sido confeccionado comparativamente, teniendo en cuenta la repetición de los símbolos y su interpretación en culturas de lugares y tiempos distintos, así como fuentes variadas como la antropología, la mitología, la historia de las religiones, el esoterismo, la emblemática, el psicoanálisis, etc. $(1958,11)$. Sin embargo, en esta segunda edición cambió el título quizá por la consideración de que en tal diccionario hay mucho de su propia vivencia y experiencia personal de los símbolos. El mismo Cirlot en el artículo "Bronwyn. Simbolismo de un argumento cinematográfico" (1970) se refiere al simbolismo como una disciplina que facilita conocimientos, pero estos conocimientos en última instancia son interpretados, comprendidos y, sobre todo, vividos individual y personalmente:

El simbolismo solo facilita conocimientos "relacionales", es decir, traducciones de unos órdenes fenoménicos a otros, porque si se refiere a principios trascendentes estos requieren, para ser utilizados y vividos, la creencia en su realidad. El simbolismo alude, como hemos visto, a concepciones del universo, a místicas y religiones, a mitos, pero no se pronuncia en cuanto a la concreta apertura de estos mundos al que los intuye o estudia. (1970a, 627)

En este mismo artículo, Cirlot sigue explicando que el significado del símbolo al final escapa a lo comprensible e interpretable, para poder ser captado únicamente como vivencia, es decir, el símbolo puede explicarse, pero el significado del símbolo - como vimos que defendía Gilbert Durand- va más allá de la explicación. Esto sitúa al símbolo, sin duda, cerca de la concepción simbólica de Cirlot sobre la poesía, que alude a un ámbito de lo desconocido y misterioso, a un ámbito que rebasa lo meramente intelectual. Estas son las palabras de Cirlot acerca del símbolo como vivencia, concretamente en referencia a su obra Bronwyn: 
Saber que el bosque es el templo para el celta acaso sea menos efectivo que sentir la belleza mágica del bosque, la misteriosidad de sus verdes claroscuros. La comunicación no intelectual de las imágenes: Bronwyn en las aguas cenagosas, Bronwyn con la corona de flores blancas en su boda, Bronwyn a la luz del amanecer tras la noche de entrega al Señor de la guerra, Bronwyn por el campo recogiendo hierbas, es más poderosa que la corroboración del sentido de estos actos o que la misma dilucidación -que no descarta una variable relatividad- de su naturaleza humana-sobrehumana. Por ello, tal vez la mejor respuesta a un mensaje de naturaleza emocional sea también la de carácter emocional, como la música o la poesía. Explicar el símbolo de algo no es probar la verdad en sí de las realidades aludidas por ese símbolo. (1970a, 627)

En relación con esto, Andrés Ortiz-Osés, en un artículo en el que repasa la hermenéutica simbólica en España, escribe precisamente que Cirlot “define la interpretación a lo Jung: como una amplificación que lleva a cabo el símbolo. El símbolo, que unifica sin confundir los contrarios, es la comunicación con lo incomunicable, posibilitando la circulación de los diferentes niveles de la realidad" (156).

Hasta ahora hemos analizado el modo en que Cirlot entiende el símbolo y a continuación veremos que esta concepción comparte muchos rasgos con su pensamiento sobre la poesía. Por ello, podemos hablar de una poética simbólica, puesto que considera la poesía como descubridora y vinculante de lo oculto personal, algo que puede interpretarse, comprenderse y explicarse, pero cuya naturaleza -como opinaba también sobre el símbolo- va más allá y requiere de la vivencia. Esta idea de la poesía como un vínculo descubridor de lo personal oculto, alejado de lo consciente, la formula en un texto titulado "El poeta" de su obra Árbol agónico (1945):

Ese hombre de cabellera dispersa, no es otra cosa que el exhumador de un mundo antes irredento. Ha aprendido, sufriendo, fórmulas mágicas que los otros desconocen: conjuros para evocar y recrear las danzas interiores.

Razas sordomudas, perdidas en sus parajes profundos, cobran voz bruscamente y, desde el valle dormido bajo la niebla, ese coral suena iluminando regiones desoladas o magníficas. Así, hasta que toda la tierra se convierte en eco. $(1945,71)$

Como vemos en este texto, para Cirlot el poeta es un exhumador o desenterrador de mundos, en concreto, de mundos interiores propios, de mundos que 
descubre a través de la poesía y que se encuentran en su interior. De aquí proviene la metáfora del poeta como buscador en lo subterráneo de su persona, en este espacio individual que se contrapone a lo sensible y exterior y al que se llega a través de la poesía y del símbolo y no a través de los sentidos y las circunstancias espaciotemporales propias, pero que no por ello se trata, como afirmaba Corbin, de algo menos real, pues lo imaginal es otro tipo de realidad, solo que no sensible. Además, Cirlot sostiene en este fragmento que esos mundos antes de ser desenterrados se encuentran irredentos, es decir, que el acto de descubrirlos y expresarlos poéticamente supone una especie de redención y de liberación.

Para seguir entendiendo la concepción simbólica que Cirlot tenía de la poesía, es muy interesante comentar unos apéndices publicados en el volumen de su poesía recogida y editada póstumamente en 2008 que se titula Del no mundo. Poesía 1961-1973. Entre tales apéndices encontramos unos textos encabezados así: "Apuntes sobre poesía” (2008, 895-901), en los que hay un epígrafe titulado “¿Qué es poesía?”, donde Cirlot afirma que junto con las palabras del poema surge el espíritu del poeta, algo en consonancia con la idea del poeta como descubridor introspectivo de su personalidad oculta a través de la poesía-símbolo; pero también recoge la concepción macrocósmica del símbolo afirmando que el universo entero es una escritura que sigue un ritmo común, términos propios de la teoría del ritmo común simbólico que se encuentra en el universo de Marius Schneider al que hemos hecho referencia:

Hay que reconocer que el poema no surge, aunque se haya dicho, como resultado de las palabras, sino que con estas surge del espíritu del poeta.

Hemos de admitir una pre-poesía en el estado de ánimo poético. Una poesía difusa en los hechos, en la realidad, en la naturaleza.

A los que digan que poesía es solo escritura, les diré que el universo es una escritura. Las constelaciones son escritura, una cadena de montañas tiene un ritmo como un verso, y el sonido del mar también lo tiene.

Los sentimientos primordiales también tienen ritmos y elementos (bellezas, analogías). (2008, 897)

En este fragmento, Cirlot hace referencia a una pre-poesía que se encuentra, por un lado, en el estado de ánimo poético y, por otro, de modo difuso en los hechos, en la realidad, en la naturaleza. Esa pre-poesía parece algo no super- 
ficial y concreto, sino oculto en uno mismo y en el mundo, lo cual el poeta percibe y expresa a través de la poesía y del símbolo liberando como un desenterrador lo poético.

Otro de los epígrafes de estos apuntes sobre poesía se titula "Finalidades de la poesía" (2008, 900), entre las que se encuentra la siguiente: "Vivir imaginativamente, a un grado de mayor intensidad, lo que no se vive realmente". En esta nota señala que el grado de vivencia de lo existencial y de lo imaginal es distinto, siendo de mayor intensidad el no sensible. Esta misma idea la encontramos en un artículo de Cirlot que se titula "Los sentimientos imaginarios. De Sartre a Bronwyn (Rosemary Forsyth)" en el que habla de "sentimientos imaginarios" como aquellos "que se deben a estímulos de realidad secundaria" $(1968,593)$, mientras que los "sentimientos reales" son "los despertados por seres, sucesos, entidades que se hallan dentro del mundo, del mundo inmediato al que experimenta emociones a su propósito" $(1968,593)$, para añadir a continuación que los sentimientos imaginarios

no lo son tanto porque el objeto que los despierta sea irreal, absoluta o relativamente (una joven apenas entrevista, una actriz de cine, una novia perdida por muerte o por su desamor, etc.), cuanto por definirlos la "intensa actividad" de la mente que los experimenta, los vive y los ensalza. Los "sentimientos imaginarios" resultan, a esta luz, no en un nivel inferior al de los sentimientos normales, sino superior. Son el patrimonio de almas capaces de ser estimuladas por ideas, por imágenes, por meras visiones de belleza. (1968, 593-94)

El último de estos "Apuntes sobre poesía" que comentaremos se titula precisamente "La poesía" $(2008,901)$. En él caracteriza a la poesía por un movimiento doble: uno que avanza y otro que desciende. El que avanza se caracteriza por ser técnico e intelectual, consciente en definitiva, y con él parece hacer referencia a la parte de la inteligencia con la que el poeta estudia y desarrolla un estilo y una técnica formal, pues, como decíamos antes, la poesía de Cirlot se diferencia de la surrealista en tener un procedimiento consciente y no ser automática. Sin embargo, el movimiento descendente lo caracteriza como "anonadante", esto puede entenderse como emocional y vivencial, y además "místico", un rasgo que ya hemos señalado aquí, pues se abre paso hacia una "zona indefinible", con lo que parece hacer referencia a esa parte desconocida, profunda y de difícil representatividad propia de la persona y hacia la que tiende la poesía simbólica: 


\section{La poesía}

Es un avance hacia un horizonte; avance que solo puede producirse con repetidos ajustes en el movimiento y lo dado por él. Pero, a la vez, es un descenso hacia una zona indefinible, situada en la intersección o en la ausencia de todas las formas reales. Los dos movimientos, de avance y descenso, son equivalentes y, a la vez que divergen, convergen. Divergen porque el movimiento de avance es inteligente y "técnico", mientras el de descenso es anonadante y "místico". Convergen porque la autenticidad, valía e intensidad de cada uno de ellos determina y aumenta la del otro, justificándola y dándole existencia. $(2008,901)$

De acuerdo con la idea de poética simbólica que acaba de verse en las teorías de Cirlot, Carlos Bousoño afirma que el simbolismo, también llamado por él irracionalismo, es una característica que la poesía occidental lleva desarrollando desde finales del siglo XIX y que consiste en "la utilización de palabras que nos emocionan, no o no solo en cuanto portadoras de conceptos, sino en cuanto portadoras de asociaciones irreflexivas con otros conceptos que son los que realmente conllevan la emoción" (26). Esta emoción no se relaciona, por tanto, con el significado lógico o literal del enunciado poemático, sino que "su relación únicamente existe con respecto a un significado oculto (oculto también, por supuesto, para el propio poeta) que es el verdadero sentido de la dicción poemática" (26). De modo que Carlos Bousoño considera que la poesía que se viene desarrollando desde poco antes del siglo XX se caracteriza porque su emoción poética se relaciona directamente con un significado oculto, que podríamos definir como poético-simbólico en el sentido que venimos desarrollando al seguir las ideas poéticas de Cirlot.

No obstante, a continuación comentaremos quizá el texto más revelador acerca del pensamiento poético simbólico de Cirlot, que es el fragmento que escribió con el título de "Poética" para una antología titulada Antología de poesía cotidiana que se publica en 1966:

\section{Poética}

Creo que el hombre es hijo del Misterio. La poesía es la búsqueda de contacto con esa zona oscura materna, en la que emerge la delgada figura de nuestro yo, en el círculo más amplio e impreciso de lo que "encontramos" en torno a ese eje solitario. La poesía no puede ser sino entrega y espera hasta el instante en que algo parece darse y esclarecerse. Posi- 
blemente es solo la ilusión de una iluminación, de una gnosis, pero, sin embargo, me es imposible apartarme de la creencia (más que de la idea) de que la poesía es eso, hundimiento para hallar. Desde el lado objetivo, poesía auténtica es la que alinea hallazgos valederos, es decir, a la vez únicos -signo de ese otro misterio que consiste en que el Ser acontezca en seres- y colectivos, signo de la comunidad que nos une a todos y nos vertebra en el gran puzle del Hombre Universal. [...] De otro lado, la poesía no se conforma con lo escrito. Poesía es un arte de conocer el mundo, de tocar una piedra, de respirar una temperatura, de soñar -de verascon el otro, con los otros mundos. Poesía es ver, entender, descifrar y a la vez no ver ni entender ni descifrar. Es levantar los brazos hacia lo que nos espera, a su vez, a nosotros. (1966, 283-84)

En este texto encontramos muchos de los elementos que venimos comentando. "El hombre es hijo del Misterio", es decir, participa de una realidad con distintos ámbitos, donde algunos se encuentran ocultos, son misteriosos; y la poesía, como el símbolo, sirve como vínculo revelador -él usa los términos: "iluminación", "gnosis"- de tales espacios desconocidos de lo real humano. Por tanto, la poesía es "una búsqueda" en una "zona oscura" de la que "emerge" el "yo", algo que concuerda con la idea, que hemos señalado ya, del poeta como exhumador, desenterrador, que busca en lo subterráneo de sí mismo y del mundo. La poesía es un "hundimiento para hallar": de nuevo encontramos la referencia a que la poesía es un movimiento descendente, como escribía Cirlot en el epígrafe "La poesía" $(2008,901)$ de sus "Apuntes sobre poesía", lo cual relacionaba él mismo con un aspecto del misticismo. Así pues, parece claro que este rasgo caracteriza a su concepción poética como un proceso de introspección. Por último, formula la contradicción de que la poesía es "un arte de conocer el mundo" y, sin embargo, de "no ver ni entender ni descifrar". Con esta contradicción está declarando que entiende la poesía de modo simbólico como algo que expresa lo desconocido y recóndito, pero que tras expresarlo, no lo agota en su significado. Volvemos a repetir la caracterización de Gilbert Durand sobre el símbolo: "su significado es imposible de presentar" (12-13), el significado del símbolo rebasa su presentación, es plural y abierto, es figura que constituye una fuente de ideas, como dice Garagalza (1990, 50), y, como expresa Cirlot, aunque se puede comprender e interpretar, en última instancia va más allá y se presta a la vivencia personal (1970a, 627).

Desde esta concepción de poesía, se podría decir que la palabra es sonido que revela lo desconocido revelado, puesto que tras ser revelado con- 
tinúa siendo desconocido, ya que, pese a prestarse a la comprensión y a la interpretación, siempre queda una dimensión de significado extra, que no se agota. Sin embargo, la palabra poético-simbólica queda ahí, como vínculo, como camino hacia esa dimensión desconocida para que podamos recorrerla con la intención de seguir encontrando en la búsqueda nuevos significados que revelen ese otro ámbito misterioso, no sensible, trascendente y profundo, propio de lo personal y del mundo. En el no entender se encierra parte de la magia y del atractivo de esta poesía simbólica, puesto que, junto con la interpretación y la vivencia de lo poético simbólico, se puede intuir que siempre hay un campo aún mayor donde queda lo oculto. Cirlot opinaba que lo simbólico va más allá de la interpretación y en última instancia ha de ser vivido. Mauricio Beuchot en El camino de la bermenéutica analógica escribe: "El mediador es analógico, la mediación implica analogicidad, y el símbolo, como ya decía Kant, solo se puede interpretar mediante la analogía, precisamente porque el símbolo representa por analogía" (133). Es decir, el símbolo y la poesía simbólica nos vinculan con un ámbito desconocido, misterioso, un ámbito que siempre desborda a la interpretación, así que no nos desvelan ese ámbito porque su naturaleza no puede ser completamente desvelada, pero nos conectan con ello. Como escribe Cirlot: "Poesía es ver, entender, descifrar y a la vez no ver ni entender ni descifrar".

Esto sugiere que, en la idea de la poesía simbólica como búsqueda en lo misterioso y desconocido, está a su vez implícita la idea de límite, puesto que lo desconocido es lo que hay más allá de un límite hasta el que podemos conocer. En el caso de la poética de Cirlot, el límite se encuentra entre lo externo y sensible, aquello que percibimos por los sentidos en nuestras circunstancias espacio temporales, y lo interno, lo imaginal o lo que pertenece a otras circunstancias espacio temporales que no son las nuestras, siendo todo ello ese ámbito recóndito con el que la poesía y el símbolo establecen un vínculo. Cirlot habla de esta idea de límite en relación con la poesía en su artículo "La vivencia lírica" de 1946:

Estamos ya ante lo desconocido. Cuando Neruda dice:

Mi corazón, es tarde y sin orillas,

sobrepasa una de las imágenes necesarias de la poesía lírica; la de ribera, de margen; la expresión de límite, elevada a su mayor intensidad. Peligrosamente, se tiene la noción de que "se está llegando" a regiones ignoradas donde se abre un desfiladero de esmeraldas. 
Sin intentar convertir a la poesía en una especie de metafísica anárquica, sí, indudablemente, es preciso probar que toda gran poesía como posición que es total, del hombre ante sí y ante el universo exterior, presupone una intuición de esas realidades y de los problemas que entrañan. Se ve forzada a trabajar sobre ellos, dejando a los superficiales el aturdimiento solo instintivo y la adoración perenne ante las apariencias que no despiertan en sus mansas mentalidades la necesidad de las profundas interrogaciones. $(1946,680)$

En el mismo sentido, más allá del límite se encuentra lo ausente. Eso que venimos denominando lo desconocido, lo natural, lo imaginal, es lo que se escapa a los sentidos, a la realidad exterior, a las circunstancias de espacio y tiempo de una persona y, por tanto, como decimos, se encuentra ausente. Hemos caracterizado ya a Bronwyn, el personaje principal al que se dirige la voz poética del ciclo de poesía más representativo de Cirlot, como un ente de ficción cuya presencia es imposible. De hecho, se puede entender todo el ciclo-compuesto por dieciséis obras en torno a Bronwyn- como un diálogo en el que la voz poética emite su voz, pero no encuentra respuesta. No lo llamamos monólogo o soliloquio, porque en ellos no hay intención de encontrar una voz que responda. En cambio, el ciclo de Bronwyn es el caso de un intento de diálogo por parte de una voz que no es respondida. Sin embargo, hay una excepción que confirma la regla dentro del ciclo y es la obra Con Bronwyn (1970) donde la voz poética propia de estos poemas se señala en cursiva y hace apelaciones a Bronwyn, las cuales esta vez sí obtienen respuesta en otra voz diferente, que por su contenido bien podría entenderse como la de la propia Bronwyn:

Los álamos inciertos de las almas

se alejan por el campo.

Los álamos se alejan, Bronwyn.

Los gritos permanecen y el incendio. (1970b, 390)

Poema al que le sigue otro escrito en letra redonda y en el que una voz poética pregunta a otra si creía que no le oía. Esto permite identificar a esta voz poética nueva con la de Bronwyn, puesto que la voz principal del ciclo hubiera podido deducir de la ausencia y de la falta de respuesta que Bronwyn no le oía:

¿Creíste que no te oía

cuando dijiste:

subes bajo las verdes nubes, 
de la tierra que hiciste

blanca en un mediodía

rojo como la herida en que perdiste

lo que a tu corazón te unía?

¿Creíste que no te oía

más allá de las olas

cuando las sombras solas

eran mi todavía? (1970b, 391)

Siguiendo con el concepto de ausencia, nos parece muy certera una cita que Clara Janés usa en referencia a la poesía de Cirlot y que toma de La Poésie moderne et le sacré de Jules Monnerot: "la poesía es oración a la ausencia" (2008, 39). Esta cita se acopla muy bien a la poética simbólica de Cirlot porque para este autor la poesía no solo es vínculo a lo misterioso y desconocido, que se encuentra más allá del límite de los sentidos y de las circunstancias espaciotemporales propias, sino que tiende a considerar lo que se encuentra en ese espacio, que sitúa en lo introspectivo, como sagrado. De hecho, Bronwyn en algunos poemas es llamada Daena, esto es, como explica el propio Cirlot, según la religión del antiguo Irán, un ángel femenino con el que el espíritu se encuentra en el puente Cinvat al emigrar en busca de la patria celeste al tercer día de morir. Allí, encuentra a su Daena, "ángel femenino que es la parte superior de su propio espíritu y cuya belleza es proporcional a la de la conducta que el humano observó en la tierra" (1970c, 11). También Bronwyn es llamada en ocasiones Schekina, "entidad que los exégetas del cabalismo denominan «lado femenino de Dios»” (1970c, 11). Así pues, por referirse a lo ausente, que es localizado de modo introspectivo, y que en ocasiones es considerado como sagrado, el término oración tiene sentido en referencia a la poesía simbólica de Cirlot, además de por ser una búsqueda y una llamada a lo que el mundo no es y no da.

Por otro lado, la poesía simbólica de Cirlot no solo establece un vínculo con lo ausente, sino que además lo invoca, pide su presencia. Esto mismo sostiene Cirlot acerca de la poesía en su artículo "La vivencia lírica" (1946), en el que escribe que la poesía solicita una aparición:

Para redimir el conflicto entre las cosas de la soledad, para restablecer la dimensión exterminada del tiempo, para llegar a un jardín en el que los deseos irrealizados tengan su fuente o su árbol mágico que canta, para reconstruir con las esencias de los más hondos momentos de ternura, de 
abandono, o de exaltación, algo de lo que ha sido una vida humana, un pensamiento humano, para elevar ese castillo transparente entre las nieblas y los mediodías, para conservar atados frente al silencio sus movimientos arrebatadores o postrados, es para lo que existen las tentativas de la poesía. Ella está siempre más allá de todo lo que por su mediación se realiza.

Así, es una aparición lo que se solicita: un descenso y una comprobación de lo que tiembla, de ese "algo con alas de pájaro que entre los labios y la voz se va muriendo”. $(1946,681)$

Esto mismo lo podemos comprobar también en muchos de sus poemas. Por ejemplo, en el antepenúltimo verso del primer poema de Bronwyn I, es decir, en el primer poema dirigido a Bronwyn de todo el ciclo, ya la voz poética expresa su deseo de que Bronwyn venga, aparezca:

Las huellas de tus dedos

no se ven en la torre.

Pero yo leo sin descanso, en la soledad de la ermita junto al mar

los antiguos signos en donde tú estuviste hacia el año mil, por los bosques, los pantanos, las ramas y las hojas, la arcilla pisada.

Dentro del corazón está la muerte como una runa blanca de ceniza.

Acércate por el campo blanco o por el verde campo o por el campo negro, pero ven.

Detente ante la tumba

donde los dos estamos. $(1967,61)$

En este sentido, Clara Janés escribe: "La finalidad de la poesía es, por tanto, para Cirlot, restablecer la esencia, el ser -lo que no es palpable-, sin duda alguna para poder conocerla, y así poseerla y llegar a ser" $(1996,15)$.

\section{El no ser en la poesía de Cirlot}

Este ámbito de lo desconocido, lo ausente, lo imaginal, con el que la poesía simbólica de Cirlot trata de establecer una conexión es llamado por Cirlot desde su teoría ontológica y en muchos de sus poemas como no ser. Según la ontología de Cirlot, que desarrolla entre otras obras en Del no mundo (1969), 
"algo viene al ser-dejando-de-ser-rodeado-de-no ser" (1969b, 419). Atendiendo a esta afirmación, la concepción del ser de Cirlot es heraclitana, es decir, considera al ser como algo en perpetuo cambio. En el proceso de cambio, el ser deja de ser para llegar a ser otra cosa. Sin embargo, el pensamiento ontológico de Cirlot es nihilista. El mismo Cirlot define nibilismo en su Diccionario de los ismos como "tendencia al acabamiento" $(1949,441)$. Decimos que es nihilista porque en su concepción del ser como cambio hace hincapié en el hecho de que el ser deja de ser, más que en el hecho de que un nuevo ser se crea. Para Cirlot, el ser se convierte permanentemente en no ser, el ser da lugar en su proceso de cambio a constante ausencia. Contradictoriamente, para Cirlot lo ausente está en permanente presencia, su concepción del ser se basa en que este es constante producción de no ser, el ser es no ser. Esto es algo que expresa por ejemplo en el siguiente fragmento del poemario Bronwyn, z (1969), donde además alude a la doble persona de Bronwyn, por un lado, como personaje de ficción cinematográfica y, por otro, como actriz de carne y hueso, cuyo nombre era Rosemary Forsyth:

Tu imagen no aparece o si aparece

es rauda, transparente,

hecha de conmoción

de yuxtaposiciones velocísimas

del ser y del no ser, como tu doble persona. (1969c, 315)

$\mathrm{Al}$ protagonismo que Cirlot da a la ausencia, al no ser o dejar de ser, a la carencia, es a lo que se refiere Clara Janés en estas líneas:

Así el tiempo hace que todo lo existente sea-dejando-de-ser, convirtiéndolo de este modo en ausencia. Por ello todo el sistema de pensamiento que Cirlot resume en los aforismos Del no mundo, consistirá en un entramado de carencias.

La vida y la muerte serán carencias, el dolor y el amor producidos por una carencia, la realidad, irrealidad, el mundo, el lugar donde nada permanece. De este modo Cirlot lleva al límite la afirmación de Rimbaud en Une Saison en Enfer: "la verdadera vida está ausente" -cuyo contenido los surrealistas incorporan a su credo- $y$ hace de ello el tema de sus diversos cantos de la "vida muerta" ya que la muerte es justamente esa ausencia. (1996, 27) 
$\mathrm{Si}$, como hemos dicho, aquello con lo que la poesía simbólica de Cirlot trata de establecer un vínculo es con lo ausente, entonces, lo ausente es, por un lado, lo introspectivo, lo imaginal, lo que no está en el mundo exterior y perceptible por los sentidos, y, por otro lado, lo que es ajeno a las circunstancias espaciales y temporales de la persona, de modo que lo que se encuentra en sitios o momentos lejanos es susceptible de ser considerado como no ser para Cirlot. Por ello, muchas de sus obras se caracterizan, como atestiguaba en el fragmento "El poeta" de Árbol agónico (1945), por desenterrar culturas antiguas. Al igual que como Cirlot había caracterizado la poesía en textos como "Apuntes sobre poesía" (2008, 895-901) o "Poética" (1966, 283-84), la arqueología es también un movimiento de búsqueda descendente, pero, en este caso, no en el ámbito personal, sino en el del mundo. Además, la arqueología tiene también relación con el no ser, con lo ausente, puesto que como dice Cirlot en su Diccionario de los ismos, el arqueologismo es "la atención hacia lo destruido por el tiempo" (1949, 94).

Cirlot también se refiere a lo que no es como lo muerto y considera que la muerte está en el pasado y en el presente, puesto que el presente es, como acabamos de decir, una fuente continua de cambio y, por tanto, de destrucción de lo que es. Puede parecer chocante que para Cirlot la muerte no está en el futuro, pero esto se explica porque Cirlot tiene un pensamiento panteísta, es decir, para él la muerte del ser humano no es una cesación completa, sino que, como le escribe a Carlos Edmundo de Ory en una carta de 1971, la muerte es solo "cambiar de postura" (1945-1971, carta de 14 de enero de 1971), puesto que en su opinión, cuando morimos el ser disgregado que somos como individuos pasa a formar parte del Todo, motivo por el que se puede calificar su ontología como panteísta. En la entrevista que José Cruset le hace, Cirlot trata este tema al ser preguntado por el concepto de "vida-muerta", que aparece por ejemplo en sus varias obras que llevan el título de Canto a la vida muerta, a lo que él responde:

En realidad es un concepto ya expresado por Séneca en sus "Cartas a Lucilio". La muerte no está en el futuro, sino en el pasado (y en el presente); es cuanto se pierde, disemina, disgrega, se aparta. Y cuanto se anhela y no se tiene. Muerte es vida carencial; nuestra vida es una "casivida". (Cruset 58)

Así pues, cuando la voz poética del ciclo Bronwyn trata de establecer un vínculo, un camino simbólico, con Bronwyn, que es lo ausente, lo imaginal, puede referirse a ella como lo sagrado que habita en el no ser: 
No ceso, Bronwyn, de pensar en ti, sabiendo que no existes ni en lo no. Teniendo ante mi espíritu una idea en desaparición constituyéndose.

No son lamentaciones ni esperanzas lo que debe ofrecer mi pensamiento a tu imagen perdida en la espiral del bosque del martirio del no ser. Eres el resplandor con que la nada habla de eternidad pero en lo nunca.

Es inútil que siga bendiciéndote:

huésped de los alteres del incendio. (1971a, 456)

Del concepto de no ser, se derivan otros que también participan del lenguaje nihilista de la negación, como lo nunca, la nada o lo no. De hecho, una de las obras poéticas de Cirlot se titula Donde lo nada nunca ni, I y II (1971).

\section{CONCLUSIONES}

Hay una relación entre el concepto de símbolo como vínculo que une al ser humano con un ámbito propio, natural o imaginal, del que se encuentra alejado, ya sea por la cultura, o por no ser propio del mundo exterior y sensible, y la visión poética de autores como Juan Eduardo Cirlot, que, por ello, podríamos denominar como simbólica. Desde este punto de vista, el símbolo y la poesía se asemejan en que se dirigen hacia un ámbito cuyo conocimiento no es cerrado, sino que siempre sobrepasa el intento de abarcar su significado.

Del mismo modo, la antropología o el misticismo consideran el símbolo como un camino que nos lleva al conocimiento de una parte del ser humano de la que nos encontramos alejados. En el caso de la antropología, es la cultura la que nos aleja cada vez más de la esencia humana; en el del misticismo, hay una creencia en una realidad no sensible, imaginal, con la que el símbolo conecta al ser humano.

Sin embargo, de acuerdo con teóricos como Carlos Bousoño, la visión de la poética simbólica no es solo una concepción característica de algunos autores, sino un rasgo propio de la emoción que suscita la poesía que viene cultivándose desde finales del siglo XIX y que se caracteriza por tener relación con un significado oculto, más que con la literalidad del poema. 
En las ideas de Cirlot sobre poesía podemos encontrar muchas desarrolladas teóricamente en las que señala a lo simbólico como propio de lo poético, pero que también tienen su reflejo en la práctica poética que llevó a cabo. Cirlot entendía la poesía como un vínculo hacia lo misterioso, hacia lo desconocido de su propia persona o del mundo, hacia lo que él denominó como no ser, ya sea en el ámbito imaginal refiriéndose a aspectos de su persona, propios -como explicaría Corbin- de un mundo intermedio entre las puras ideas y lo sensible, o en el ámbito de sus circunstancias, por ejemplo temporales, refiriéndose a culturas antiguas, como la de Cartago o muchas otras que explora en su poesía.

Con la idea de que la poesía simbólica busca ahondar en lo misterioso y lo desconocido, aparece la idea de límite, que Cirlot señala como muy relevante en poesía. Esto se debe a que el límite señala la frontera entre lo conocido y lo desconocido, siendo el plano de lo misterioso hacia donde se dirige la búsqueda de la poesía simbólica. Sin embargo, Cirlot caracteriza la poesía en dos direcciones: una que avanza, de tipo intelectual y técnico; y otra que desciende, de tipo emocional, que es la que introspectivamente busca en lo ausente. Cuando la ausencia pertenece al ámbito personal, esa introspección puede considerarse como un rasgo en común entre la poesía simbólica de Cirlot y la literatura mística, pues los místicos buscaban lo sagrado en su interior, así como en la obra de Cirlot titulada el ciclo de Bronwyn, por ejemplo, muchas veces se hace referencia a Bronwyn como propia del ámbito interno de la voz poética. Cuando la ausencia se da en el ámbito del mundo, la poesía de Cirlot se emparenta con la arqueología, que es la atención a lo destruido por el tiempo.

\section{OBRAS CITADAS}

Beuchot, Mauricio. En el camino de la bermenéutica analógica. Salamanca: Editorial San Esteban, 2005.

Bousoño, Carlos. Superrealismo poético y simbolización. Madrid: Gredos, 1979. Cirlot, Juan Eduardo. Árbol agónico. 1945. En la llama: poesía (1943-1959). Ed. Enrique Granell. Madrid: Siruela, 2005. 69-123.

Cirlot, Juan Eduardo. Correspondencia entre fuan Eduardo Cirlot y Carlos Edmundo de Ory. Obra inédita, manuscritos consultados en la Fundación Carlos Edmundo de Ory, Cádiz: 1945-1971.

Cirlot, Juan Eduardo. "La vivencia lírica”. Entregas de poesía 19. 1946. En la llama. Poesía (1943-1959). Ed. Enrique Granell. Madrid: Siruela, 2005. 674-81. 
Cirlot, Juan Eduardo. Diccionario de los ismos. 1949. Eds. Victoria Cirlot y Lourdes Cirlot. Madrid: Siruela, 2006.

Cirlot, Juan Eduardo. Diccionario de símbolos. 1958. Ed. Victoria Cirlot. Madrid: Siruela, 2013.

Cirlot, Juan Eduardo. "Poética". Antología de poesía cotidiana. Ed. Antonio Molina. Madrid/Barcelona: Alfaguara, 1966. 283-84.

Cirlot, Juan Eduardo. Bronwyn, I. 1967. Bronwyn. Ed. Victoria Cirlot. Madrid: Siruela, 2001. 59-91.

Cirlot, Juan Eduardo. "Los sentimientos imaginarios: de Sartre a Bronwyn (Rosemary Forsyth)". 1968. Bronwyn. Ed. Victoria Cirlot. Madrid: Siruela, 2001. 593-96.

Cirlot, Juan Eduardo. Bronwyn, VI. 1969a. Bronwyn. Ed. Victoria Cirlot. Madrid: Siruela, 2001. 201-25.

Cirlot, Juan Eduardo. Del no mundo. 1969b. Del no mundo: poesía (1961-1973). Ed. Clara Janés. Madrid: Siruela, 2008. 415-28.

Cirlot, Juan Eduardo. Bronwyn, z. 1969c. Bronwyn. Ed. Victoria Cirlot. Madrid: Siruela, 2001. 311-33.

Cirlot, Juan Eduardo. "Bronwyn: simbolismo de un argumento cinematográfico”. 1970a. Bronwyn. Ed. Victoria Cirlot. Madrid: Siruela, 2001. 609-28.

Cirlot, Juan Eduardo. Con Bronwyn. 1970b. Bronwyn. Ed. Victoria Cirlot. Madrid: Siruela, 2001. 385-409.

Cirlot, Juan Eduardo. "Lo eterno femenino: Daena y Schekinah". La vanguardia española (4 agosto 1970c): 11.

Cirlot, Juan Eduardo. Bronwyn, w. 1971a. Bronwyn. Ed. Victoria Cirlot. Madrid: Siruela, 2001. 433-77.

Cirlot, Juan Eduardo. La quête de Bronwyn. 1971b. Bronwyn. Ed. Victoria Cirlot. Madrid: Siruela, 2001. 479-522.

Cirlot, Juan Eduardo. Del no mundo: poesía (1961-1973). Ed. Clara Janés. Madrid: Siruela, 2008.

Corbin, Henry. Cuerpo espiritual y tierra celeste. 1979. Trad. Ana Cristina Crespo. Madrid: Siruela, 1996.

Cruset, José. "Juan Eduardo Cirlot: la poesía, sustitución de lo que el mundo no es". La vanguardia española (30 marzo 1967): 58.

Durand, Gilbert. La imaginación simbólica. 1968. Trad. Marta Rojzman. Buenos Aires: Amorrortu, 2007.

Garagalza, Luis. La interpretación de los simbolos: hermenéutica y lenguaje en la filosofía actual. Barcelona: Anthropos, 1990. 
Garagalza, Luis. Introducción a la bermenéutica contemporánea: cultura, simbolismo y sociedad. Rubí (Barcelona): Anthropos, 2002.

Goethe, Johann Wolfgang von. "Sobre el simbolismo". 1818. Fragmentos para una teoría romántica del arte. Ed. Javier Arnaldo. Madrid: Tecnos, 2014. $165-66$.

Janés, Clara. Cirlot, El no mundo y la poesía imaginal. Madrid: Huerga y Fierro, 1996.

Janés, Clara. "Inmersión en el abismo". Juan Eduardo Cirlot. Del no mundo: poesía (1961-1973). Ed. Clara Janés. Madrid: Siruela, 2008. 17-45.

Ortiz-Osés, Andrés. "La recepción de la hermenéutica en España”. Isegoría 5 (1992): 154-60.

Paz, Octavio. Los hijos del limo. Barcelona: Seix Barral, 1974.

Schaffner, Franklin. El señor de la guerra (DVD). Tenerife: Usa Visión, 2008.

Wahnón, Sultana. Saber literario y hermenéutica: en defensa de la interpretación. Granada: EUG, 1991.

Wahnón, Sultana. "Teoría literaria y hermenéutica: para otra ética de la interpretación”. Perspectivas actuales de bermenéutica literaria: para otra ética de la interpretación. Ed. Sultana Wahnón. Granada: EUG, 2014. 25-66. 

Entre literatura y arte:

hermenéuticas intermediales 
